\title{
Daily ration and feeding periodicity of some fishes off the coast of Namibia
}

\author{
E. Macpherson \\ Instituto de Investigaciones Pesqueras, Paseo Nacional s/n, 08003 Barcelona, Spain
}

\begin{abstract}
We studied feeding habits of Coelorhynchus fasciatus (Günther, 1877), Helicolenus dactylopterus dactylopterus (Delaroche 1809), and Lophius upsicephalus Smith, 1841. The exponential model of Elliott \& Persson (1978) was used to estimate the daily ration of C. fasciatus, with estimates ranging from 0.55 to $2.15 \%$ wet body weight. The method of Diana was applied to calculate the daily ration and feeding intensity of $H$. d. dactylopterus ( 0.16 to $0.68 \%$ wet body weight) and $L$. upsicephalus $(0.55$ to $1.60 \%$ wet body weight). C. fasciatus feeds all day long; the other 2 species are basically daytime feeders.
\end{abstract}

\section{INTRODUCTION}

With growing interest in multispecific relations of fish populations, numerous papers aimed at quantifying the amount of food eaten by various species have appeared in recent years. A number of different methods, mainly based on the relation between growth and metabolic requirements (e.g. Kitchell et al. 1977 , Kitchell \& Breck 1980, Majkowski 1981) or on estimates of daily ration (e.g. Jobling 1981, Durbin et al. 1983), have been used. Despite methodological problems chiefly related to estimating the digestion rate, this latter group of methods is more widely accepted and is more easily applied in studies of trophic interrelationships and, in general, in multispecies assessments.

Elliott \& Persson (1978) and Jobling (1981) suggested a series of models for estimating daily rations of fish which are in practice relatively easy to apply and which have since been employed by different authors (e.g. Lane et al. 1979, Cochran \& Adelman 1982, Durbin et al. 1983, Worobec 1984). However, as Diana (1979) pointed out, the equations used assume that fish eat continuously, which is not the case for all species, and he put forth an alternative, simpler model for predators that remain inactive for certain periods or spend time searching for prey. The utilization of one or the other of these models therefore depends on more complete knowledge of the predation habits of the species involved, e.g. their feeding cycle and frequency.
The object of the present study was to analyze these factors in order to determine the most appropriate method of calculating the daily rations of 3 species frequently taken off the coast of Namibia: Coelorhynchus fasciatus (Günther, 1877), Helicolenus dactylopterus dactylopterus (Delaroche, 1809), and Lophius upsicephalus Smith, 1841. This latter species is also an important predator of commercial species (Merluccius capensis, Todarodes sagittatus, etc.) (Macpherson 1983), hence estimates of its daily ration have direct application in the population dynamics of these exploited stocks.

\section{MATERIAL AND METHODS}

Stomachs were collected in 24 h periods: Coelorhynchus fasciatus (Oct 1, 2, 1981, Mar 20, 1982, and Jun 14-15, 1982, Aug 16, 1983); Helicolenus dactylopterus dactylopterus (Aug 19, 1981, Sep 25-26, 1981, Jun 14-15, 1982, Aug 16, 1983). Lophius upsicephalus stomachs were collected on Jun 14-15, 1982 and Aug 16,1983 , with supplementary information being collected during other sampling operations carried out at different times of day in January-February and July -August 1984

Four to 6 hauls were made at regular intervals in each 24 h period. Elliott \& Persson (1978) stated that an interval of about $3 \mathrm{~h}$ was appropriate for calculating daily rations, larger intervals giving rise to bias. This possible source of error is relevant only in the case of Coelorhynchus fasciatus. 
At least 20 specimens were examined from each haul. Lengths ranged from 15 to $29 \mathrm{~cm}$ for Coelorhynchus fasciatus and Helicolenus dactylopterus dactylopterus, and from 30 to $59 \mathrm{~cm}$ for Lophius upsicephalus. The sampling area was between $24^{\circ} 00^{\prime} \mathrm{S}$ and $26^{\circ} 00^{\prime} \mathrm{S}$ at 300 to $350 \mathrm{~m}$, with an average temperature of $9.5^{\circ} \mathrm{C}$ for all samples (range: 8 to $10^{\circ} \mathrm{C}$ ).

Fish weight was measured directly in each sample. Stomach contents were preserved in alcohol and identified to species where possible. Individual prey items were weighed separately after being dried with tissue paper to remove surface moisture. Small-sized prey items (polychaetes, tiny crustaceans) were grouped for each stomach. The original weight of prey items was calculated from whole prey using conversion factors derived from fresh samples and the relation between weight and length of otolith, carapace, or other structure closely related to prey weight or length.

Most methods of determining the daily ration (e.g. Elliott \& Persson 1978, Jobling 1981) assume continuous feeding. What is more, when feeding rhythm is estimated solely on the basis of the ratio of the percent stomach weight to predator weight (\% BW), it is subject to error if there is a broad range of mean values for the samples (Jenkins \& Geen 1977). In order to determine these factors and to ascertain more accurately the daily feeding cycle, the extent of digestion undergone by the different prey items in each stomach was taken into account employing a 4-stage scale, ranging from intact prey to advanced digestion, similar to scales utilized by other authors (e.g. Daan 1973, MacDonald et al. 1982). Furthermore, the percentage of full stomachs in each haul was used as complementary information concerning feeding activity.

No significant differences were found among the different length classes of these 3 species for stomach weight (expressed as \% BW), percentage of full stomachs, or digestion stage of prey items, and for this reason all the stomachs collected from each haul were pooled.

Evacuation of prey from fish stomachs describes an exponential function (e.g. Elliott \& Persson 1978, Huebner \& Langton 1982), though some authors have also used a square root function (e.g. Jobling 1981). In any case, as Brodeur (1984) points out, the differences between the two are very small.

The exponential function, and hence the model of Elliott \& Persson (1978), was used in the present study:

$$
C_{1}=\frac{R t\left(S_{t}-S_{0} e^{-R t}\right)}{1-e^{-R t}}
$$

where $C_{t}=$ food intake over the time interval from $t_{0}$ to $t_{1}$, calculated on the basis of the amount of food in the stomach at times $t_{0}\left(S_{0}\right)$ and $t_{1}\left(S_{t}\right)_{i} R=$ instantaneous coefficient of gastric evacuation.
This model assumes that fish eat continuously over the interval of time $t$. As pointed out by Elliott \& Persson (1978), the interval t should preferably be $3 \mathrm{~h}$ or less, though this value may vary depending on species and prey items studied. The daily ration $(D R)$ is calculated by summing the values of $C_{1}$ for all intervals sampled during the $24 \mathrm{~h}$ period.

The standard error for the daily food intake was estimated using the equation given by Worobec (1984).

The instantaneous coefficient of gastric evacuation $\left(\mathrm{R}, \mathrm{h}^{-1}\right)$ was calculated from the results of various authors (see Worobec 1984 and references therein). As these authors state, research has indicated that the type of food and temperature are the main factors influencing the value of $R$, such that at a given temperature $R$ is similar for fish feeding on a given type of prey and is independent of predator and prey size. From experimental data, Worobec (1984) found that the relation between $R$ and temperature ( $T$ ) for fish feeding on small prey (polychaetes, small crustaceans) could be described as:

$$
R=-0.0442+0.0175 T\left(r^{2}=0.62 ;\right. \text { d.f. 34) }
$$

The digestion rate for fish as prey is slower than that for small crustaceans and polychaetes (e.g. Durbin et al. 1983). From experimental data reported by Daan (1973), Jones (1974), Diana (1979), and Brodeur (1984), the relation between $\mathrm{R}$ and $\mathrm{T}$ for fish-eating predators was estimated to be:

$$
\mathrm{R}=0.00408+0.00527 \mathrm{~T}\left(\mathrm{r}^{2}=0.95 ; \text { d.f. } 5\right)
$$

Persson (1984) stated that the value of $R$ may be altered if fish feed several times a day rather than once a given amount of time after completing digestion of the previous prey item. This aspect of digestion of prey comprises a major stumbling block for calculating $\mathrm{C}_{\mathrm{t}_{1}}$ as discussed by several authors (Tyler 1970, Noble 1973, Jones 1974).

Nevertheless, the values found by Tyler (1970) and Jones (1974) for different predators, prey, and temperatures exhibited a certain consistency, the value of $R$ being 1.6 times (range: 1.4 to 1.8 times) greater when fish engaged in feeding at regular intervals rather than the practice of single feeds after extended periods. Pending further data, a value of $R^{\prime}=1.6 \mathrm{R}$ can $\mathrm{f} u r n i s h$ a rough approximation of the value of $C_{1}$.

When a predator feeds at regular intervals, the model of Elliott \& Persson (1978) for estimating the daily ration has to be modified. As these and other authors (Worobec 1984) have pointed out, when fish are trophically inactive after ingesting a prey, digestion of such prey can be described by the equation:

$$
\mathrm{S}_{\mathrm{t}}=\mathrm{S}_{0} \quad \mathrm{e}^{-\mathrm{Rt}}
$$

where $S_{t}=$ food weight at end of digestion period 
(arbitrarily considered to be $2 \%$ of its initial weight); $\mathrm{S}_{0}=$ initial weight of prey; $\mathrm{R}=$ instantaneous coefficient of gastric evacuation; $\mathrm{t}=$ digestion time.

On the other hand, Diana (1979) stated that for predators that remain trophically inactive between ingestion of one prey item and their next feeding, the most appropriate equation is:

$$
\mathrm{DR}=\frac{\overline{\mathrm{W}} \times \mathrm{N}_{\mathrm{F}}}{\mathrm{DT} \times \mathrm{N}_{\mathrm{t}}}
$$

where $D R=$ daily ration (in $\mathrm{g}$ or $\% \mathrm{BW}$ ); $\overline{\mathrm{W}}=$ mean initial weight of prey (in $g$ or $\% B W$ ); $N_{t}=$ number of stomachs sampled; $N_{F}=$ number of full stomachs; $\mathrm{DT}=$ digestion time for prey items in days, as estimated from Equation (4). A similar method was used by Jones \& Geen (1977) to calculate the daily ration for Squalus acanthias.

Diana (1979) defined feeding intensity, or the time between feeds, as:

$$
\mathrm{FI}=\mathrm{DT} \times \mathrm{N}_{\mathrm{l}} / \mathrm{N}_{\mathrm{F}}
$$

where FI = time between feeds, in days.

According to Worobec (1984), the standard error for the daily ration (Equation 5) (see also Box et al. 1978, p. 563) can be expressed as the sum of the standard errors for each of the parameters used. Assuming that these are mutually independent, the error is thus expressed by:

$\sigma_{D R}=\left[\left(\frac{\delta f}{\delta W} \sigma_{W}\right)^{2}+\left(\frac{\delta f}{\delta N_{F}} \sigma_{N_{F}}\right)^{2}+\left(\frac{\delta f}{\delta R} \sigma_{R}\right)^{2}\right]^{1 / 2}$

Expressing $N_{1}$ and $N_{F}$ in percent, Equation (5) then becomes:

$$
\mathrm{DR}=\frac{\overline{\mathrm{W}} \times \mathrm{N}_{\mathrm{F}}}{\mathrm{DT} \times 100}
$$

DT is calculated from Equation (4), bearing in mind that $S_{1}$ is $2 \%$ of $S_{0}$ :

$$
\mathrm{DR}=\frac{\overline{\mathrm{W}} \times \mathrm{N}_{\mathrm{F}} \times \mathrm{R}}{0.163 \times 100}
$$

In other words

$$
\begin{aligned}
& \left(\frac{\delta \mathrm{f}}{\delta \mathrm{W}} \sigma_{\mathrm{W}}\right)^{2}=\left(\frac{\mathrm{N}_{\mathrm{F}} \times \mathrm{R}}{16.30}-\sigma_{\mathrm{W}}\right)^{2} \\
& \left(\frac{\delta \mathrm{f}}{\delta \mathrm{N}_{\mathrm{F}}} \sigma_{\mathrm{N}_{\mathrm{F}}}\right)^{2}=\left(\frac{\mathrm{W} \times \mathrm{R}}{16.30} \sigma_{\mathrm{N}_{\mathrm{F}}}\right)^{2} \\
& \left(\frac{\delta \mathrm{f}}{\delta \mathrm{R}} \sigma_{\mathrm{R}}\right)^{2}=\left(\frac{\mathrm{W} \times \mathrm{N}_{\mathrm{F}}}{16.30} \sigma_{\mathrm{R}}\right)^{2}
\end{aligned}
$$

$\sigma_{R}$ was calculated from the regression of $\mathrm{R}$ on $\mathrm{T}$ following the method of Sokal \& Rolf (1969, p. 420-428).

\section{RESULTS}

\section{Coelorhynchus fasciatus}

A total of 714 stomachs were examined. The diet consisted primarily of polychaetes and small benthic crustaceans (amphipods, mysids, Calocaris barnardi, etc.). No major differences were observed among length groups

The percentage of empty stomachs, stomachs containing undigested prey, and the weight of prey (in \% BW) per sample are shown in Fig. 1. In any given stomach, numerous polychaetes and small crustaceans, which have similar instantaneous coefficients of evacuation (R) (MacDonald et al. 1982), could be found in various stages of digestion. No clear trend could be identified in the daily cycle in relation to the percentage of undigested prey items and other percentage measures used. All these factors would seem to indicate that Calocaris fasciatus feeds more or less indiscriminately throughout the day, and the model of Elliott \& Persson (1978) was therefore used to estimate the daily ration (DR).

Table 1 presents the different values for the daily ration and their respective standard errors in percent wet fish weight ( $\%$ BW), obtained using the value of $\mathrm{R}$ calculated by Equation (2) and $\mathrm{R}^{\prime}=1.6 \mathrm{R}$. The daily ration ranged from 0.55 to $1.3 \% \mathrm{BW}$ or from 0.84 to $2.15 \% \mathrm{BW}$ (if $\mathrm{R}^{\prime}$ was used), the lowest values corresponding to October, the highest to March and August.

\section{Helicolenus dactylopterus dactylopterus}

In all, 647 stomachs from the various samples were examined. The diet was composed primarily of benthic crustaceans (Calocaris barnardi, Bathynectes piperitus, Pterygosquilla armata capensis, etc.). Some 80 to $90 \%$ of the stomachs contained a single prey item only. Polychaetes and small crustaceans were sometimes found in stomachs of individuals from the smaller length groups, but always along with a larger prey item of the kind indicated above. Average initial stomach weight ranged between 0.63 and $1.23 \%$ BW (Table 2).

The different $24 \mathrm{~h}$ periods studied showed well defined, constant patterns. The percentage of stomachs containing undigested, i.e. recently swallowed, prey was higher $(80$ to $90 \%)$ in the daytime, chiefly between 9:00 am and 3:00 pm. This cycle was found in all samples taken (Fig. 2); the various prey items also followed this same pattern and hence were all grouped together. The percentage of empty stomachs also showed a definite pattern, though not as clearly as that for the stomachs containing undigested prey items just described. Nevertheless, a negative correlation was 


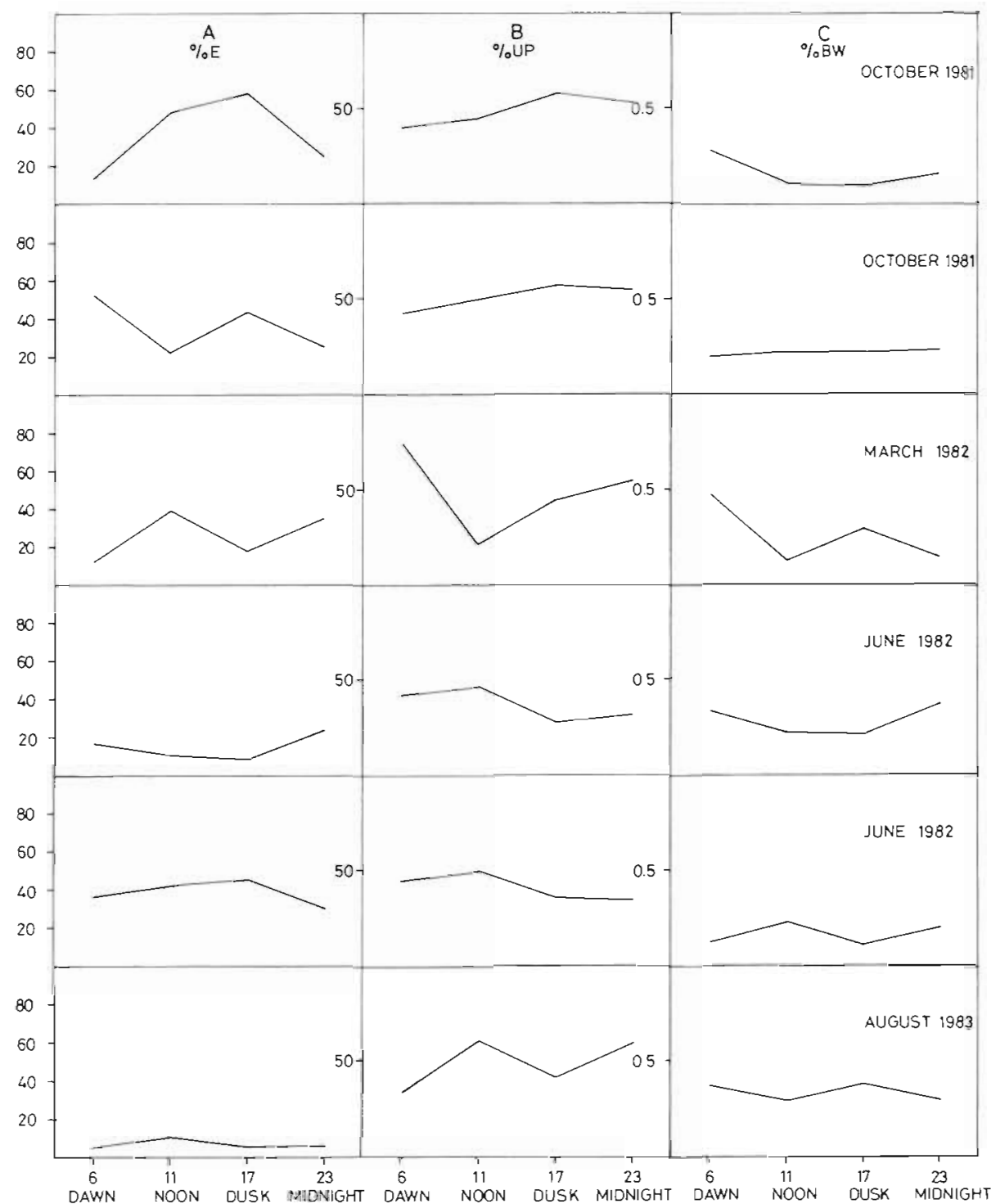

Fig. 1. Coelorhynchus fasciatus. Daily cycle of $(A)$ empty stomachs (expressed as \% total number of stomachs); (B) percentage of stomachs containing undigested prey (expressed as \% total number of food-containing stomachs); (C) weight of prey $(\% \mathrm{BW})$, including empty stomachs

found for such stomachs in 4 of the 6 sampling periods (Fig. 2)

If more than 1 prey item was present in a stomach,

Table 1. Coelorhynchus fasciatus. Estimate of daily ration (DR) expressed as \% body weight, (A) using $R=0.122$ calculated from Equation (2), (B) using $R^{\prime}=1.6 R$ (see text); $\mathrm{N}=$ number of specimens in samples; $\overline{\mathrm{S}}=$ mean weight of stomach contents at capture (per cycle) (\% BW)

\begin{tabular}{|lrrrrrc|}
\hline & \multicolumn{4}{c}{$\mathrm{A}$} & \multicolumn{2}{c|}{$\mathrm{B}$} \\
& $\mathrm{N}$ & $\mathrm{DR}$ & $\sigma_{\mathrm{DR}}$ & $\mathrm{DR}$ & $\sigma_{\mathrm{DR}}$ & $\overline{\mathrm{S}}$ \\
\hline Oct 1981 & 169 & 0.55 & 0.75 & 0.84 & 0.85 & 0.179 \\
Oct 1981 & 173 & 0.70 & 1.10 & 1.17 & 1.29 & 0.223 \\
March 1982 & 100 & 1.05 & 0.88 & 1.47 & 1.02 & 0.272 \\
Jun 1982 & 92 & 0.79 & 0.90 & 1.29 & 0.96 & 0.248 \\
Jun 1982 & 84 & 0.86 & 0.76 & 1.43 & 0.82 & 0.333 \\
Aug 1983 & 96 & 1.30 & 1.44 & 2.15 & 1.43 & 0.455 \\
\hline
\end{tabular}

they tended to be in the same stage of digestion, suggesting that Helicolenus dactylopterus dactylopterus is primarily a daytime predator feeding during a relatively short period, after which it remains inactive. Such feeding behaviour indicated that the model of Diana (1979) was the most appropriate for estimating the daily ration (DR). The DT value obtained using Equation (4) was $1.34 \mathrm{~d}$. This value was the same for all samples, since temperature was constant throughout. Since $H$. dactylopterus dactylopterus feeds mainly between 9:00 am and 3:00 pm, the maximum value recorded during those hours was taken as the value of $N_{F}$ for each sampling period

Table 2 shows results obtained together with values of the parameters applied and their standard errors. Daily ration (DR) ranged from 0.16 to $0.68 \% \mathrm{BW}$; feeding intensity (FI) was 1.8 to $3.9 \mathrm{~d}$, with minimum values recorded in June. 
Table 2. Helicolenus dactylopterus dactylopterus. Estimate of daily ration (DR) expressed as \% fish body weight (\% BW) and feeding intensity (FI) in days, calculated from Equations (5) and (6). $N=$ number of specimens in samples; $\bar{W}=$ initial mean weight of food ingested ( $\% \mathrm{BW}$ ); $\overline{\mathrm{N}}_{\mathrm{F}}=$ mean percentage of food-containing stomachs (see text). Instantaneous coefficient of evacuation $(\mathrm{R}=0.122)$ was calculated from Equation (2)

\begin{tabular}{lrrrrrrrrr}
\hline & $N$ & $\bar{W}$ & $\sigma_{w}$ & $\bar{N}_{f}$ & $\sigma_{N F}$ & DR & $\sigma_{D R}$ & FI \\
\hline Aug 1981 & 95 & 0.94 & 0.92 & 66.0 & 11.31 & 0.46 & 0.46 & 2.0 \\
Sept 1981 & 87 & 0.88 & 1.10 & 52.5 & 14.85 & 0.35 & 0.44 & 2.6 \\
Sept 1981 & 99 & 0.86 & 1.13 & 48.5 & 0.71 & 0.31 & 0.41 & 2.8 \\
Jun 1982 & 142 & 0.63 & 0.24 & 34.7 & 5.03 & 0.16 & 0.07 & 3.9 \\
Jun 1982 & 134 & 0.65 & 0.26 & 38.7 & 5.04 & 0.19 & 0.08 & 3.5 \\
Aug 1983 & 90 & 1.23 & 0.76 & 74.3 & 12.86 & 0.68 & 0.42 & 1.8 \\
\hline
\end{tabular}

\section{Lophius upsicephalus}

Analysis of the 453 stomachs collected indicated that the diet consisted principally of fish (Merluccius capensis, Macruridae, etc.), and to a lesser extent cephalopods (Todarodes sagittatus). All the food-containing stomachs held a single prey item (or, very
Fig. 2. Helicolenus dactylopterus dactylopterus. Daily cycle of (A) empty stomachs (expressed as \% total number of stomachs); (B) percentage of stomachs containing undigested prey (expressed as $\%$ total number of food-containing stomachs); (C) weight of prey $(\%$ BW $)$, including empty stomachs

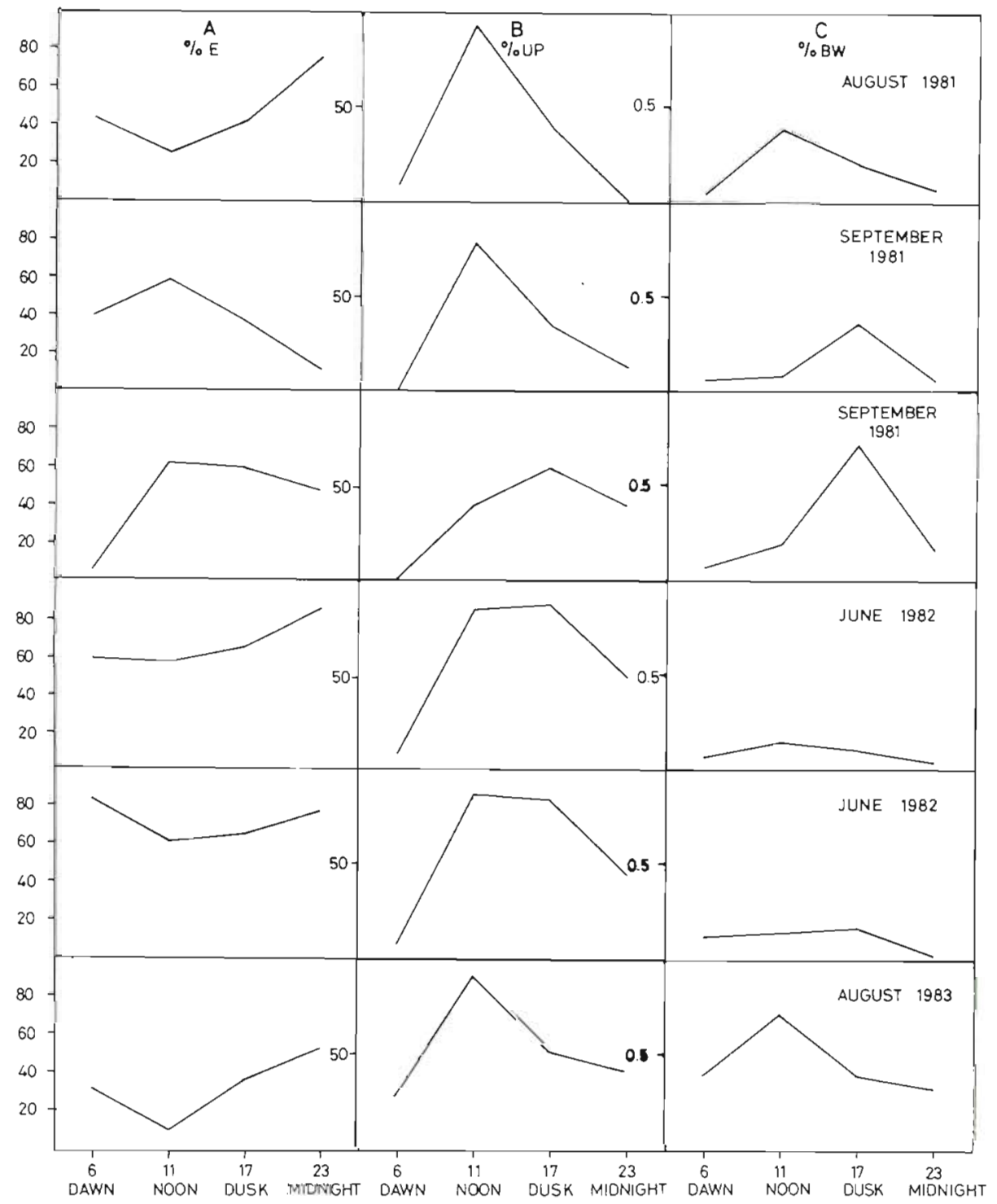


Table 3. Lophius upsicephalus. Estimate of the daily ration (DR) expressed as \% fish body weight (\% BW) and feeding intensity $(F I)$ in days, calculated from Equations (5) and (6). $\mathrm{N}=$ number of specimens in the samples; $\bar{W}=$ initial mean weight of food (\% BW) $; N_{F}=$ mean percentage of food-containing stomachs (see text). Instantaneous coefficient of evacuation ( $R=0.054$ ) was calculated from Equation (3)

\begin{tabular}{|c|c|c|c|c|c|c|c|c|}
\hline & $\mathrm{N}$ & $\bar{W}$ & $\sigma_{w}$ & $\bar{N}_{i}$ & $\sigma_{N F}$ & $\mathrm{DR}$ & $\sigma_{\mathrm{DR}}$ & FI \\
\hline Jun 1982 & 165 & 15.19 & 9.47 & 31.8 & 6.81 & 1.60 & 1.40 & 9 \\
\hline Jun 1982 & 162 & 8.49 & 3.16 & 33.4 & 11.79 & 0.94 & 0.66 & 9 \\
\hline Aug 1983 & 120 & 9.54 & 5.11 & 33.3 & 6.06 & 1.05 & 0.79 & 9 \\
\hline Jan 1984 & 274 & 10.58 & 6.75 & 15.7 & 16.47 & 0.55 & 0.64 & 19 \\
\hline Aug 1984 & 286 & 12.00 & 7.13 & 30.8 & 17.30 & 1.22 & 1.17 & 10 \\
\hline
\end{tabular}

rarely, two). In the infrequent cases where 2 prey items were found, both were in the same stage of digestion. Table 3 gives the initial stomach weight in \% BW. Large variation in the mean weight is observable, as a result of this species' strategy of indiscriminate hunting from ambush (Macpherson 1983).

There was close agreement among the 3 sampling periods studied, with a higher proportion of stomachs containing undigested prey at daybreak and during the morning hours (Fig. 3). This pattern is corroborated by the occurrence of Merluccius capensis and Todarodes sagittatus in the diet, since both these species migrate away from the bottom at night. The cycle of empty stomachs did not display as clear a trend, because the digestion time for prey items was longer than 24 h (Fig. 3).

These results suggest that Lophius upsicephalus is basically a daytime predator that remains inactive once it has captured its prey, like Helicolenus dactylopterus dactylopterus. Consequently, Diana's (1979) Equation (5) was used to estimate the daily ration. The
DT (digestion time) value was calculated from Equation (4), but with a different value of $\mathrm{R}$ estimated using Equation (3). At a temperature of $9.5^{\circ} \mathrm{C}, \mathrm{R}=0.054$. Substituting into Equation (4) gave a DT of $3.02 \mathrm{~d}$. Given the nature of the daily cycle of $L$. upsicephalus, suggesting greater daytime activity not reflected in the percentage of full stomachs due to the slow digestion rate, the value of $N_{F}$ in Equations (5) and (6) could be calculated from samples taken at any time of day.

Additional samples taken at different times of day on different days, though in the same area, in January -February 1984 and July-August 1984 indicated a similar diet, with July-August $N_{F}$ values similar to those for the previous sampling periods (29.9 to $31.7 \%$ ) and somewhat higher than the January-February values (13.8 to $19.1 \%)$.

Daily ration and feeding intensity are shown in Table 3. Values of DR and FI ranged from 0.55 to $1.60 \%$ BW and from 9 to $19 \mathrm{~d}$, respectively, food intake being lowest in January-February and highest in June-August.

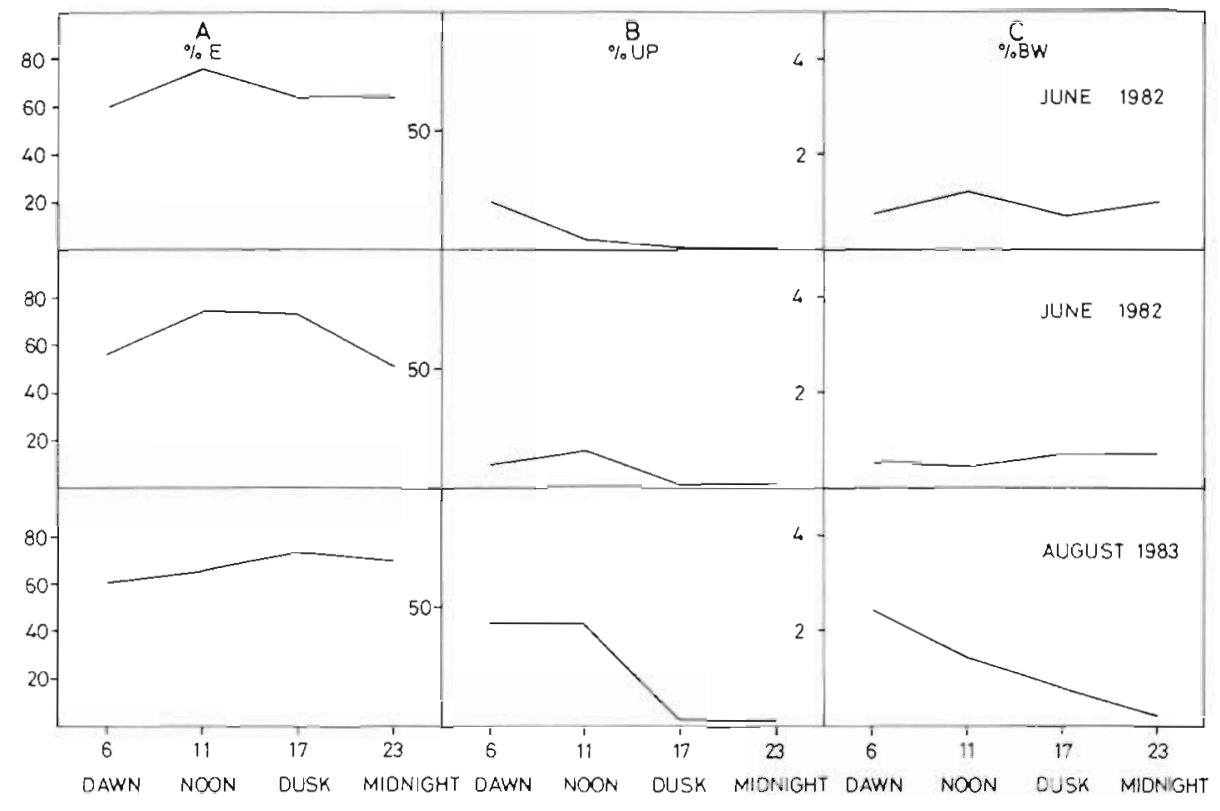

Fig. 3. Lophius upsicephalus. Daily cycle of (A) empty stomachs (expressed as \% total number of stomachs); (B) percentage of stomachs containing undigested prey lexpressed as \% total number of food-containing stomachs); (C) weight of prey $(\% \mathrm{BW}), \quad$ including empty stomachs 


\section{DISCUSSION}

As stated by Worobec (1984), the error in the calculation of $\mathrm{C}_{t}$ is mainly dependent upon $\mathrm{R}, \mathrm{S}_{1}$, and $\mathrm{S}_{0}$. The accuracy of these latter two can be improved by increasing sample size. The calculation of $R$ may pose a problem, since experimental data tend to be scarce, and there may be large variations when predators feed again before fully digesting the previous prey item (Persson 1984). The apparent consistency observable in studies on this feature (Tyler 1970, Jones 1974) may reduce the sources of error. The effect of reducing the error in $\mathrm{R}$ is lower than that of reducing the error in other parameters (Cochran \& Adelman 1982, Worobec 1984), and further research is needed to accurately determine daily consumption in this type of predator.

The equations of Diana (1979) considerably simplify the calculations and methods for ascertaining the daily ration. In the case of predators which ingest their prey over a short space of time, sampling during the periods of highest activity provide the information needed to calculate the daily ration. The value of $\mathrm{R}$ and hence of digestion time (DT) is the most questionable factor, since the other parameters ( $W$ and $N_{F}$ ) are readily obtainable from the samples. Since neither Lophius upsicephalus nor Helicolenus dactylopterus dactylopterus ingest prey until the previous prey item has been digested, there is no error due to overlapping feeds.

Estimation of the daily consumption of each prey type is simplified if, as in Coelorhynchus fasciatus, the value of $\mathrm{R}$ is the same for all prey items. The occurrence of fish and cephalopods in Helicolenus dactylopterus dactylopterus individuals larger than $25 \mathrm{~cm}$ means that from that length group estimates of daily ration vary somewhat, and further research is required. However, such prey items were disregarded, given their low frequency in the samples. The increased proportion of cephalopods in the stomachs of Lophius upsicephalus larger than $50 \mathrm{~cm}$ likewise implies a change in $\mathrm{R}$ and hence in the daily ration.

It is difficult to compare daily consumption in the 3 species studied with values reported in the literature, because methodology tends to differ (cf. Thorpe 1977 , Nakashima \& Leggett 1978, Lane et al. 1979, Cochran \& Adelman 1982, Durbin et al. 1983, Ryer \& Boehlert 1983, Worobec 1984). Certain authors reported the times between feeds: Diana (1979) mentioned $2.8 \mathrm{~d}$ in summer and $25 \mathrm{~d}$ in winter in Esox lucius, and Jones \& Geen (1977) gave $16 \mathrm{~d}$ as a year-round average in Squalus acanthias. In general, a species' food intake increases with temperature and during periods of rapid growth.

Given the scant information available on the biology of the 3 species studied, it is difficult to relate the differences in daily consumption to their habits and metabolic requirements. All 3 species exhibit relatively sedentary habits. Lophius upsicephalus (daily ration $[\mathrm{DR}]=0.55$ to $1.60 \% \mathrm{BW}$ ) remains partly buried in the bottom for long periods, capturing its prey from ambush (e.g. Keenleyside 1979). The increase in activity detected in January-February did not appear to be related to enhanced abundance of its staple prey item (Merluccius capensis) during these months (Macpherson et al. 1984). Since the diet of $L$. upsicephalus, like that of most ambush feeders, is correlated to prey abundance, differences in feeding activity may be due to internal rhythms independent of food availability.

Helicolenus dactylopterus dactylopterus (DR $=0.16$ to $0.68 \% \mathrm{BW}$ ), like other proximal species (e.g. Keenleyside 1979), remains inactive for relatively large periods of the day. The low level of daily consumption recorded in June was due both to reduced feeding intensity and to lower stomach weight. In the samples taken during that month, feeding intensity levels were similar, but the mean weight of prey ingested (chiefly Calocaris barnardi) was lower than in the rest of the samples, in which the prey items (Pterygosquilla armata capensis, Bathynectes piperitus) were somewhat larger.

Coelorhynchus fasciatus ( $\mathrm{DR}=0.55$ to $1.30 \% \mathrm{BW}$ or 0.85 to $2.15 \% \mathrm{BW}$ if $\mathrm{R}^{\prime}=1.6 \mathrm{R}$ ) is, though a poor swimmer, an active species, with a faster growth rate than the other two (Morales pers. comm.). Its predatory activity, more or less constant throughout the day, would explain its higher DR value.

Because of the sensitivity of the Elliott \& Persson model (1978) to the $S_{0}$ and $S_{t}$ values and of the Diana model (1979) to the $W$ and $N_{F}$ values, day-to-day and regional variations (Nakashima \& Leggett 1978, Smagula \& Adelman 1982) may have considerable impact on the calculation of daily consumption. For this reason, as Worobec (1984) pointed out, caution is in order when extrapolating from results for a small number of samples. The high standard error in the daily ration of Coelorhynchus fasciatus may be due to 2 main factors: inherent variance in the stomach contents, and utilization of wet weight as a unit of measurement. As several authors have noted (e.g. Hyslop 1980), variations in the amount of liquid when weighing prey items is one of the chief sources of error. Worobec (1984) obtained a very low standard error using dry weight. Unfortunately, none of the other authors cited provided estimates of the error in the diet calculation, and so it has not been possible to arrive at any more accurate conclusions. And while dry weight yields a lower error (Berg 1979), wet weight is required for work in such areas as feeding, inter-species relationships, etc. Dry weight values obtained from the conversion of wet weight values will, logically, contain 
an error that must be taken into account when calculating the daily ration.

Acknowledgements. I thank B. Roel and R. Sacks for critically reviewing the manuscript. A. Castellon, A Roig and C. Castellon provided field assistance.

\section{LITERATURE CITED}

Berg, J. (1979). Discussion of methods of investigating the food of fishes with reference to a preliminary study of the prey of Gobiusculus flavescens. Mar. Biol. 50: 263-273

Box, G. E. P., Hunter, W. H., Hunter, I. S. (1978). An introduction to design data analysis and model building. John Wiley \& Sons, London

Brodeur, R. D. (1984). Gastric evacuation rates for two foods in the black rockfish, Sebastes melanops Girard. J. Fish Biol. 24: $287-298$

Cochran, P. A., Adelman, I. R. (1982). Seasonal aspects of daily ration and diet of largemouth bass, Micropterus salmoides, with an evaluation of gastric evacuation rates. Environ. Biol. Fish. 7: 265-275

Daan, N. (1973). A quantitative analysis of the food intake of North Sea cod, Gadus morhua. Neth. J. Sea Res. 6: $479-517$

Diana, J. S. (1979). The feeding pattern and daily ration of a top carnivore, the northern pike (Esox lucius). Can. J. Zool. 57: 2121-2127

Durbin, E. G., Durbin, A. G., Langton, R. W., Bowman, R. E. (1983). Stomach contents of silver hake, Merluccius bilinearis, and Atlantic cod, Gadus morhua, and estimation of their daily rations. Fish. Bull. U.S. $81: 437-454$

Elliott, J. M., Persson, L. (1978). The estimation of daily rates of food consumption for fish. J. Anim. Ecol. 47: 977-991

Huebner, J. D., Langton, R. W. (1982). Rate of gastric evacuation for winter flounder, Pseudopleuronectes americanus. Can. J. Fish. Aquat. Sci. 37. 2159-2168

Hyslop, E. J. (1980). Stomach contents analysis - a review of methods and their application. J. Fish Biol. 17: 411-429

Jenkins, B. W., Geen, J. M. (1977). A critique of field methodology for determining fish feeding periodicity. Environ. Biol. Fish. 1: 209-214

Jobling, M. (1981). Mathematical models of gastric emptying and the estimation of daily rates of food consumption for fish. J. Fish Biol. 19: 245-258

Jones, B. C., Geen, G. H. (1977). Food and feeding of spiny dogfish (Squalus acanthias) in British Columbia waters. J. Fish. Res. Bd Can. 34: 2067-2078

Jones, R. (1974). The rate of elimination of food from the stomachs of haddock Melanogrammus aeglefinus, cod Gadus morhua and whiting Merlangius merlangius. J. Cons. int. Explor Mer 35: 225-243

Keenleyside, M. H. A. (1979). Diversity and adaptation in fish behaviour Springer-Verlag, Berlin
Kitchell, J. F., Breck, J. E. (1980). Bioenergetics model and foraging hypothesis for sea lamprey (Petromyzon marinus). Can. J. Fish. Aquat. Sci. 37: 2159-2168

Kitchell, J. F., Stewart, D. J., Weininger, D. (1977). Applications of a bioenergetics model to yellow perch (Perca flavescens) and walleye (Stizostedion vitreum vitreum). J. Fish. Res. Bd Can. 34: 1922-1935

Lane, F. D., Kingsley, M. C. S., Thornton, D. E. (1979). Daily feeding and food conversion efficiency of the diamond turbot: an analysis based on field data. Trans. Am. Fish. Soc. 108: 530-535

MacDonald, J. S., Waiwood, K. G., Green, R. H. (1982). Rates of digestion of different prey in Atlantic cod (Gadus morhua), ocean pout (Macrozoarces americanus) winter flounder (Pseudopleuronectes americanus) and american plaice (Hippoglossoides platessoides). Can. J. Fish. Aquat. Sci. 39: 651-659

Macpherson, E. (1983). Ecología trófica de peces de la costa de Namibia. 1. Hábitos alimentarios. Res. Exp. Cient. 11: 81-137

Macpherson, E., Roel, B., Morales, B. (1984). Reclutamiento de la merluza y abundancia y distribución de diferentes especies comerciales en las Divisiones 1.4 y 1.5 durante 1983-1984. ICSEAF/84/S.P. 31, 109 p (mimeo)

Majkowski, J. (1981). A procedure for evaluating the food biomass consumed by a fish population. Can. J. Fish. Aquat. Sci. 38: 1199-1208

Nakashima, B. S., Leggett, W. C. (1978). Daily ration of yellow perch (Perca flavescens) from lake Memphemagog, Quebec-Vermont with a comparison of methods for in situ determination. J. Fish. Res, Bd Can. 35: 1597-1603

Noble, R. L. (1973). Evacuation rates of young yellow perch Perca flavescens (Hitchill). Trans. Am. Fish. Soc. 102: $759-763$

Persson, L. (1984). Food evacuation and models for multiple meals in fishes. Environ. Biol. Fish. 10: 305-309

Ryer, C. H., Boehlert, G. W. (1983). Feeding chronology, daily ration and effects of temperature upon gastric evacuation in the pipefish, Syngnatus fuscus. Environ. Biol. Fish. 9: 301-306

Smagula, C. M., Adelman, I. R. (1982). Day-to-day variation in food consumption by largemouth bass. Trans. Am. Fish. Soc. 111: $543-548$

Sokal, R. R., Rolf, F. J. (1969). Biometry: the principles and practice of statistics in biological research. $W \mathrm{H}$. Freeman, San Francisco

Thorpe, J. E. (1977). Daily ration of adult perch, Perca fluviatilis, during summer in Loch Leven, Scotland. J. Fish Biol. 11: 55-68

Tyler, A. V (1970). Rates of gastric emptying in young cod. J. Fish. Res. Bd Can. 27: 1177-1189

Worobec, M. N. (1984). Field estimation of the daily ration of winter flounder, Pseudopleuronectes americanus (Walbaum) in a southern New England Pond. J. exp. mar. Biol. Ecol. 77: 183-196 